\title{
Does endothelin-1 reduce superior mesenteric artery blood flow velocity in preterm neonates?
}

\author{
Fiona J Weir, Arne Ohlsson, Katherine Fong, Kofi Amankwah, Flavio Coceani
}

\begin{abstract}
Aim-To compare plasma endothelin-1 (ET-1) concentrations in preterm neonates from pre-eclamptic and normal mothers; and to evaluate whether ET-1 has a role in altered arterial blood flow velocity.

Methods-Umbilical arterial blood and neonatal arterial blood were sampled on days 1 and 3 for gas analysis and measurement of plasma ET-1. Doppler ultrasonography of the middle cerebral, renal, and superior mesenteric arteries (SMA) was performed.
\end{abstract}

Results-Neonates in the pre-eclampsia $(n=18)$ and control $(n=18)$ groups had mean (SD) gestational ages of $31.1(2.5)$ weeks and 30.4 (2.1) weeks; their birthweights were 1432 (SD 676) g and 1692 (SD 500) g, respectively. In the pre-eclampsia group mean umbilical arterial $\mathrm{PO}_{2}$ was lower-1.88 (0.75) $\mathrm{kPa}$ compared with 3.27 (1.41) $\mathrm{kPa}(\mathrm{p}<0.01)$ - and mean plasma ET-1 concentration was higher in the umbilical artery-40.6 (SD 15.0) compared with 30.5 (SD 13.8) $\mathrm{pg} / \mathrm{ml}(\mathrm{p}=0.04)$ and day 1 blood-54.9 (35.0) pg/ml compared with $33.6(14.6) \mathrm{pg} / \mathrm{ml}(\mathrm{p}=0.03)$. Middle cerebral artery peak systolic velocity was higher and SMA time averaged, peak systolic, and mean peak velocities were lower in the pre-eclampsia group. SMA time averaged velocity was inversely related to plasma ET-1 concentration.

Conclusion-The association between increased production of ET-1 and reduction in SMA time averaged velocity suggests a possible mechanism for hypoperfusion of the intestinal wall in neonates.

(Arch Dis Child Fetal Neonatal Ed 1999;80:F123-F127)

Keywords: eclampsia; hypoxia; vasoconstriction; endothelin-1

Department of Obstetrics and Gynaecology

K Amankwah

Maternal, Infant and Reproductive Health Research Unit

A Ohlsson

Hospital for Sick Children, Integrative Biology Program

F Coceani

Correspondence to: Dr Arne Ohlsson Department of Paediatrics Mount Sinai Hospital 600 University Street, Toronto, Ontario, M5S 1B2. Email:

aohlsson@mtsinai.on.ca

Accepted 16 October 1998 pathophysiological role in hypoxia-ischaemia, specifically as a precipitating factor in the development of necrotising enterocolitis. ${ }^{6}$

We have shown that fetal blood vessels have a functioning ET-1 system in lambs, which, depending on the site, may be activated by an increase (ductus arteriosus) ${ }^{7}$ or decrease (pulmonary vasculature $)^{8}$ in oxygen tension. In humans umbilical cord blood ET-1 concentration is raised at birth in asphyxia, ${ }^{9}$ preeclampsia, and intrauterine growth retardation. ${ }^{10-12}$ Increased circulating concentrations of ET-1 in neonates with persistent pulmonary hypertension ${ }^{13}{ }^{14}$ or respiratory distress syndrome, ${ }^{15}$ and increased urinary concentrations of ET-1 in neonates with posthypoxic renal failure ${ }^{16}$ have been described.

In pre-eclampsia reduced placental transport of oxygen and nutrients results in fetal hypoxia and often growth retardation. Clinical and animal studies suggest that an hypoxic fetus attempts to preserve cerebral perfusion at the expense of visceral perfusion. ${ }^{17}{ }^{18}$ Studies of fetuses and neonates with growth retardation or abnormal umbilical arterial blood flow velocity have shown an association between fetal hypoxia and perinatal asphyxia, hyperviscosity, necrotising enterocolitis, renal failure and haemorrhage. ${ }^{19} 20$ Nevertheless, studies have not simultaneously measured ET-1 and organ blood flow velocities.

We hypothesised that in pre-eclampsia fetal hypoxaemia upregulates the ET-1 system in blood vessels. This in turn would lead to vasoconstriction and impaired regional blood flow in the neonate. This study aimed to determine the effect of fetal hypoxaemia caused by pre-eclampsia on ET-1 production and organ blood flow velocity in preterm infants.

\section{Methods}

Mothers at risk of preterm delivery between 26 and 34 weeks of gestation, admitted to Women's College Hospital, were eligible for study. The pre-eclampsia group comprised mothers with pregnancy induced hypertension plus proteinuria, and the control group comprised mothers with normal blood pressure, in spontaneous preterm labour. Mothers were excluded if they developed chorioamnionitis, antepartum haemorrhage, or if a congenital anomaly was recognised in the infant before or after birth. Written, informed consent was obtained from mothers before delivery for participation in the study.

Venous blood from the mother was drawn before delivery. Umbilical arterial samples were obtained after double clamping the cord at birth. Arterial blood was obtained through indwelling arterial, central, or peripheral cath- 
eters, or by puncture of a peripheral artery. Blood samples were drawn at the same time as sampling of arterial blood was indicated for other purposes and when the neonates were clinically stable. Samples were obtained from the neonates at 1 to 12 hours (day 1 ) and 48 to 72 hours (day 3 ) of age. The whole blood was added to chilled, EDTA coated Microtainer tubes that were centrifuged at $4000 \mathrm{rpm}$ for 5 minutes. The plasma was collected and stored at $-80^{\circ} \mathrm{C}$.

ET-1 was extracted from plasma on SepPak C18 cartridges. Radioimmunoassay was performed, using an antibody to human ET-1 from Peninsula Laboratories. The sensitivity of the assay is about 2 pg per sample. The procedure and its validation have been reported before. $^{2}$

Doppler ultrasonography of the right middle cerebral (MCA), right renal (RA), and superior mesenteric (SMA) artery was performed within 1 hour of the blood sampling for ET-1 assay on days 1 and 3. Neonates were examined while asleep or in an awake-quiet state. In neonates receiving enteral feeds, studies were performed 90 to 120 minutes after a feed. Examinations were performed using an ATL Ultramark 9 , with a $5 \mathrm{MHz}$ phased array sector transducer. We have already reported the technique for Doppler sonography of the MCA, ${ }^{21}$ $\mathrm{RA}$, and SMA. ${ }^{22}$ All arteries were evidenced by colour Doppler imaging with flow towards the transducer mapped in red and away from the transducer in blue. The MCA was visualised between the temporal and frontal bones in an axial plane. To visualise the right renal artery, the neonate lay in a decubitus position and a coronal image of the kidney was obtained. The Doppler sample volume was placed in the proximal RA. The epigastrium was then examined. Colour Doppler imaging was used to localise the origin of the SMA from the aorta in a longitudinal plane. The Doppler sample volume was placed in the proximal SMA. A Doppler sample volume size of $1.5 \mathrm{~mm}$ was used and a wall filter of $50 \mathrm{~Hz}$ for the RA and $100 \mathrm{~Hz}$

Table 1 Characteristics (means and standard deviations) of neonates in pre-eclampsia and control groups

\begin{tabular}{|c|c|c|c|}
\hline & $\begin{array}{l}\text { Pre-eclampsia group }(n=18) \\
\text { mean }(S D)\end{array}$ & $\begin{array}{l}\text { Control group }(n=18) \text { mean } \\
(S D)\end{array}$ & $p$ Value * \\
\hline Gestation (weeks) & $31.1(2.5)$ & $30.4(2.1)$ & 0.37 \\
\hline Birthweight (g) & $1432(676)$ & $1692(500)$ & 0.20 \\
\hline \multicolumn{4}{|l|}{$\mathrm{pH}$} \\
\hline UA & $7.28(0.08)$ & $7.36(0.05)$ & $<0.01$ \\
\hline Day 1 & $7.42(0.06)$ & $7.40(0.06)$ & 0.26 \\
\hline Day 3 & $7.40(0.06)$ & $7.39(0.05)$ & 0.56 \\
\hline \multicolumn{4}{|l|}{ Arterial $\mathrm{PO}_{2}(\mathrm{kPa})$} \\
\hline UA & $1.88(0.75)$ & $3.27(1.41)$ & $<0.01$ \\
\hline Day 1 & $10.06(2.61)$ & $10.34(1.92)$ & 0.22 \\
\hline Day 3 & $10.52(3.86)$ & $10.98(1.65)$ & 0.66 \\
\hline \multicolumn{4}{|l|}{ Arterial $\mathrm{PCO}_{2}(\mathrm{kPa})$} \\
\hline UA & $7.54(0.99)$ & $6.02(1.08)$ & $<0.01$ \\
\hline Day 1 & $4.74(0.92)$ & $5.40(0.76)$ & 0.01 \\
\hline Day 3 & $5.21(0.85)$ & $5.05(0.84)$ & 0.59 \\
\hline \multicolumn{4}{|c|}{$\begin{array}{l}\text { Packed cell volume } \\
\text { (haematocrit) (\%) }\end{array}$} \\
\hline Day 1 & $0.53(0.07)$ & $0.51(0.06)$ & 0.57 \\
\hline Day 3 & $0.48(0.09)$ & $0.46(0.08)$ & 0.62 \\
\hline \multicolumn{4}{|c|}{$\begin{array}{l}\text { Mean arterial blood } \\
\text { pressure }(\mathrm{mm} \mathrm{Hg})\end{array}$} \\
\hline Day 1 & $38(6)$ & $37(5)$ & 0.83 \\
\hline Day 3 & $43(9)$ & $43(5)$ & 0.79 \\
\hline
\end{tabular}

Level of significance determined by unpaired $t$ test. for the MCA and the SMA. When indicated, angle correction was used for accurate velocity display. The optimal spectral trace from each artery containing a minimum of five consecutive waveforms was recorded on to videotape for later analysis of heart rate, peak systolic velocity (PS), end diastolic velocity (ED) and mean velocity (MV). The time averaged velocity (TAV) is calculated from the waveforms at the time of study. The examination was stopped if the neonate showed discomfort. Any left to right shunt across the ductus arteriosus was identified with colour Doppler, according to the method of Swensson et al..$^{23}$ The total examination time, including ultrasound scanning of all three vessels, was limited to $30 \mathrm{~min}-$ utes.

Parametric and non-parametric tests were used for statistical analyses. One way analysis of variance (ANOVA) was used to compare the groups for plasma ET-1 concentration, while ANOVA for repeated measures was used to compare the measurements of MCA, SMA, and RA blood flow velocity between groups. Where a significant difference in TAV between groups was found, linear regression was used to establish a possible relation between mean plasma ET-1 concentration and mean TAV.

The sample size was set at 16 neonates in each group ( $80 \%$ power) to find a difference of one standard deviation in the plasma ET-1 concentration between the groups. Differences were considered significant with a $\mathrm{p}$ value of $<$ 0.05 .

The study received approval from the Women's College Hospital Research Ethics Committee and the Hospital for Sick Children Research Ethics Committee.

\section{Results}

There were 17 mothers and 18 neonates in each group. In the pre-eclampsia group 16 mothers were treated with antihypertensive drugs, four had abnormal coagulation, and seven had abnormal liver function tests, including two with hypertension, raised liver enzymes and low platelet syndrome. Thirteen mothers in the pre-eclampsia group underwent caesarean section compared with five in the control group; 12 and seven, respectively, had epidural/spinal anaesthesia; two and none, respectively, had general anaesthesia; three and 16, respectively, had spontaneous onset of labour; and eight and none, respectively, were induced. Two fetuses were known to have abnormal umbilical artery blood flow velocity. The characteristics of the groups are shown in table 1 . Fifteen neonates in the pre-eclampsia group and 14 neonates in the control group had a patent ductus arteriosus (PDA) detectable by Doppler ultrasonography on day 1; three neonates in each group had a PDA detectable on day 3. Two neonates from each group were treated with indomethacin to close the PDA, but the treatment was carried out after completion of the blood sampling and sonography. Five neonates in the pre-eclampsia group and four from the control group were treated with surfactant for respiratory distress syndrome. There were no statistical differences 


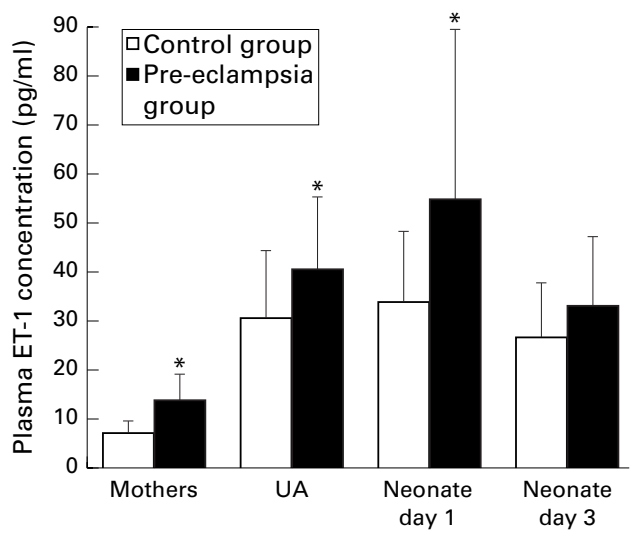

Figure 1 Mean (SD) plasma ET-1 concentration in control and pre-eclampsia groups. ${ }^{\star} p<0.05$ compared with control group.

between the groups at the time of study in respiratory support (ventilator rate, pressures, and inspired oxygen concentration).

The plasma ET-1 concentrations were significantly higher in the pre-eclampsia group, specifically in maternal venous blood $(\mathrm{p}=0.012)$, the umbilical artery $(\mathrm{p}=0.044)$ and in day 1 neonatal arterial blood $(\mathrm{p}=0.027)$. The results are shown in fig 1 .

Sonographic studies were discontinued before completion in a few neonates either because they were disturbed or because it was impossible to visualise adequately the RA or SMA due to breathing movements or intestinal gas shadows. Doppler studies of the MCA were completed in 16 neonates from each group, while RA and SMA were completed in matched groups of, respectively, 12 and 9 neonates. The differences in blood flow velocity measurements in the MCA, SMA, and RA between both groups are shown in table 2 . The MCA PS was significantly higher in the pre-eclampsia group compared with the control group. The TAV, PS, and MV were significantly lower in the pre-eclampsia group compared with the control group. There were no differences between the groups in RA blood flow velocity measurements.

Subsequent analysis showed that mean SMA TAV was inversely related to mean plasma

Table 2 Middle cerebral artery, superior mesenteric artery, and renal artery blood flow velocity (mean and SD) $(\mathrm{cm} / \mathrm{s})$ in pre-eclampsia and control groups

\begin{tabular}{clll}
\hline & $\begin{array}{l}\text { Pre-eclampsia group } \\
\text { mean }(S D)\end{array}$ & $\begin{array}{l}\text { Control group } \\
\text { mean }(S D)\end{array}$ & $p$ Value \\
\hline MCA & $\mathrm{N}=16$ & $\mathrm{~N}=16$ & \\
TAV & $9.5(0.6)$ & $8.6(0.6)$ & 0.28 \\
PS & $38.0(8.9)$ & $31.6(11.4)$ & 0.01 \\
ED & $8.5(5.2)$ & $7.8(3.5)$ & 0.47 \\
MV & $19.5(6.4)$ & $16.9(6.0)$ & 0.09 \\
SMA & $\mathrm{N}=9$ & $\mathrm{~N}=9$ & \\
TAV & $12.5(6.1)$ & $17.4(8.9)$ & 0.04 \\
PS & $52.3(19.8)$ & $80.2(40.4)$ & 0.01 \\
ED & $9.2(7.5)$ & $10.5(11.3)$ & 0.27 \\
MV & $20.9(10.5)$ & $33.8(17.4)$ & $<0.01$ \\
RA & $\mathrm{N}=12$ & $\mathrm{~N}=12$ & \\
TAV & $8.1(6.1)$ & $9.0(3.6)$ & 0.25 \\
PS & $39.6(15.2)$ & $40.6(21.4)$ & 0.86 \\
ED & $6.4(5.1)$ & $5.8(4.0)$ & 0.56 \\
MV & $17.3(8.0)$ & $17.5(6.8)$ & 0.92 \\
\hline
\end{tabular}

MCA = middle cerebral artery; SMA = superior mesenteric artery; RA = renal artery; TAV = time averaged velocity; PS = peak systolic velocity; $\mathrm{ED}=$ end diastolic velocity; $\mathrm{MV}=$ mean velocity.

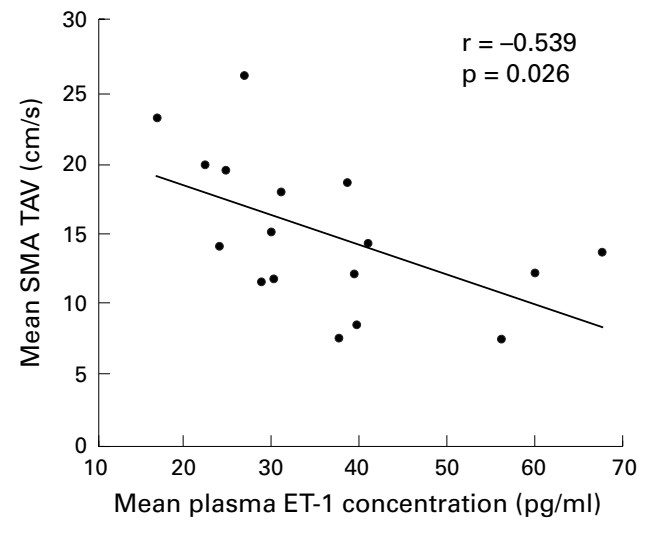

Figure 2 Correlation between mean plasma ET-1 concentration and mean superior mesenteric artery (SMA) time averaged velocity (TAV) in 17 neonates. Means represent data from days 1 and 3 of life; one neonate did not have all measurements on both days.

ET-1 concentration (means of complete data from day 1 and day 3 from 17 infants) (fig 2).

\section{Discussion}

This prospective cohort study has shown that preterm neonates of mothers with preeclampsia had fetal hypoxia, increased circulating ET-1, reduced SMA blood flow velocity and an inverse correlation between ET-1 and SMA blood flow velocity. ET-1 acts primarily in blood vessels and only under certain conditions does the compound appear in the circulation. ET-1 concentrations in arterial blood reflect primarily production by the arterial wall. The relation between blood and vascular wall concentrations is not known. Descriptive studies of plasma concentrations in human neonates have not shown an association with gestational age nor with birthweight. ${ }^{24}{ }^{25}$ In experimental studies the observed response to ET-1 seems to depend on the vascular bed and the experimental conditions. ${ }^{826-30}$ Mothers with pre-eclampsia have higher circulating ET-1 than mothers of a similar gestational age who present with preterm labour. ${ }^{31-35}$ Both low and high oxygen and shear stress may stimulate ET-1 synthesis. ${ }^{378}$ We found relative fetal hypoxia in the pre-eclampsia group, which may have stimulated the higher ET-1 concentrations observed in the fetuses and neonates. Although high plasma ET-1 concentrations have been described in sick neonates, ${ }^{15}{ }^{25}$ there were no differences between the groups in the current study with regard to severity of respiratory disease, blood pressure, or incidence of PDA, to account for the high ET-1 concentrations in the pre-eclampsia group.

Blood flow velocity measurements correlated well with actual blood flow, the best measurement being the TAV. ${ }^{36}$ We have shown that neonatal SMA blood flow velocity is reduced in a group of neonates with antenatal hypoxia. The PS, MV, and TAV were all reduced in the SMA of the pre-eclampsia group and therefore these neonates are likely to have reduced intestinal blood flow after birth. We reported measurements of blood flow velocities, as they are more reliable than the resistive or pulsatility indices. ${ }^{22}$ Studies of neonates with risk factors 
for necrotising enterocolitis have also shown lower SMA PS ${ }^{38}$ and MV. ${ }^{39}$ The reductions in SMA TAV, PS, and MV in the pre-eclampsia group were unlikely to be due to an increased incidence of PDA. PDA reduces SMA ED, ${ }^{40} 41$ but in our study ED was the same in both groups. Gestational age, birthweight, and enteral feeding are factors that may influence SMA blood flow velocity. ${ }^{42-44}$ Blood pressure ${ }^{45}$ and acid base status ${ }^{37}$ can condition blood flow velocity in cerebral arteries. The impact of these variables was minimised in our study as there were no differences in birthweight and gestational age between the groups and the studies were performed at a time when the neonates were stable. Based on these considerations, we propose that blood borne ET-1 may act as a vasoconstrictor in the SMA, thus explaining the inverse correlation between plasma concentrations of the peptide and SMA TAV. Alternatively, or additionally, changes in shear stress (blood flow velocity) may upregulate the ET-1 system in endothelial cells. ${ }^{46}$ The latter explanation better explains the persisting increase in ET-1 postnatally.

MCA PS was increased in the pre-eclampsia group. Increased cerebral blood flow has been shown in human neonates after fetal hypoxia. ${ }^{47}$ Conversely, we did not find any effect of pre-eclampsia on neonatal RA blood flow velocity despite a recent report pointing to a reduction in RA PS after fetal hypoxia. ${ }^{48}$ Why, then, is SMA selectively susceptible to the constrictor effect of ET-1? There are two possibilities that are not mutually exclusive: a greater influence of $\mathrm{ET}_{\mathrm{A}}$ over $\mathrm{ET}_{\mathrm{B}}$ receptors in that vessel or an inadequacy of local relaxing mechanisms.

In conclusion, we have shown that neonates of mothers with pre-eclampsia have increased circulating ET-1 and reduced SMA blood flow velocity, possibly due to fetal hypoxia. In preterm neonates SMA TAV, and hence, actual blood flow, is related to circulating ET-1 concentration after birth. The possibility of a causal link between ET-1 and necrotising enterocolitis raises the prospect of using an ET-1 antagonist, specifically an $\mathrm{ET}_{\mathrm{A}}$ antagonist, in the prevention and management of this disease. Further investigation is needed to confirm this particular pathophysiological role for ET-1.

We thank Mary Lou Ryan and Lois Kelsey for their excellent technical help in performing this study.

This project was made possible by support from the Garfield-Weston Foundation, the Advanced Technology Laboratories (ATL), and the Heart and Stroke Foundation of Ontario, Grant No T-3369.

1 Masaki T. Possible role of endothelin in endothelial regulation of vascular tone. Annu Rev Pharmacol Toxicol 1995;35:235-55.

2 Coceani F, Kelsey L. Endothelin-1 release from lamb ductus arteriosus: rele-vance to postnatal closure of the vessel. Can f Physiol Pharmacol 1991;69:218-21.

3 Kourembanas S, Marsden PA, McQuillan LP, Faller DV. Hypoxia induces endothelin gene expression and secretion in cultured human endothelium. f Clin Invest in cultured $1991 ; 88: 1054-7$.

4 Rakugi H, Tabuchi Y, Nakamaru M, Nagano M, Higashimori K, Mikami H, Ogihara T, Suzuki N. Evidence for endothelin-1 release from resistance vessels of rates in response to hypoxia. Biochem Biophys Res Commun 1990;169:973-7.
5 Walder CE, Thomas GR, Thiemermann C. The hemodynamic effects of endothelin-1 in the pithed rat. 7 namic effects of endothelin-1 in
Cardiovasc Pharmacol 1989;13:S93-7.

6 Kays DW. Surgical conditions of the neonatal intestinal tract. Clin Perinatol 1996;23:353-75.

7 Coceani F, Kelsey L, Seidlitz E. Evidence for an effector role of endothelin in closure of the ductus arteriosus at birth. Can $\mathcal{F}$ Physiol Pharmacol 1992;70:1061-4.

8 Wang Y, Coe Y, Toyoda O, Coceani F. Involvement of endothelin-1 in hypoxic pulmonary vasoconstriction in the lamb. F Physiol (Lond) 1995;482:421-34.

9 Isozaki-Fukunda Y, Kojima T, Hirata Y, Ono A, Sawaragi S, Sawaragi L, Kobayashi Y. Plasma immunoreactive endothelin-1 concentration in human fetal blood: its relation to asphyxia. Pediatr Res 1991;30:244-7.

10 Hartiainen-Sorri AL, Vuolteenaho O, Leppaluoto J, Ruskoaho $H$. Endothelin in umbilical artery vasospasm. Lancet 1991;337:619.

11 Schiff E, Weiner E, Zalel Y, Maschiach S, Sibai BM, Shalev E. Endothelin-1,2 levels in umbilical vein serum of intrauterine growth retarded fetuses as detected by cordocentesis. Acta Obstet Gynecol Scand 1994;73:21-4.

12 Buerni M, Morabito N, Aloisi C, et al. Endothelin-1 production from umbilical arteries of hypertensive pregproduction from umbilical arteries of hypertent

13 Rosenberg AA, Kennaugh J, Koppenhaffer SL, Loomis M, Chatfield BA, Abman SH. Elevated immunoreactive endothelin-1 levels in newborn infants with persistent pulmonary hypertension. F Pediatr 1993;123:109-14.

14 Kobayashi H, Puri P. Plasma endothelin levels in congenital diaphragmatic hernia. F Pediatr Surg 1994;29:1258-61.

15 Kaapa P, Kero P, Ekblad H, Erkkola R, Arjamaa O. Plasma endothelin-1 in the neonatal respiratory distress syndrome. Ann Chir Gyn 1994;208:110-12.

16 Sulyok E, Ertl T, Adamovits K, Hovanyovszky S, Rascher W. Urinary endothelin excretion in the neonate: influence of maturity and perinatal pathology. Pediatr Nephrol maturity and

17 Cohn HE, Sacks EJ, Heymann MA, Rudolph AM. Cardiovascular responses to hypoxemia and acidemia in fetal lambs. Am $\mathcal{F}$ Obstet Gynecol 1974;120:817-24.

18 Block BSB, Llanos AJ, Creasey RK. Responses of the growth retarded fetus to acute hypoxemia. Am $\mathcal{F}$ Obstet Gynecol 1984;148:878-85.

19 Hacket SA, Campbell S, Gamsu H, Cohen-Overbeek T, Pearce JMF. Doppler studies in the growth retarded fetus and prediction of neonatal necrotizing enterocolitis, haemorrhage and neonatal morbidity. BMF 1987;249:1316.

20 Malcolm G, Ellwood D, Devonald K, Beilby R, HendersonSmart D. Absent or reversed end diastolic flow velocity in the umbilical artery and necrotising enterocolitis. Arch Dis Child 1991;66:805-7.

21 Ohlsson A, Fong K, Ryan ML, Yap L, Smith JD, Shennan AT, Glanc P. Cerebral blood-flow-velocity measurements in neonates: technique and interobserver reliability. Pediatr Radiol 1991;21:395-7.

22 Weir FJ, Ohlsson A, Fong K, Ryan ML, Myhr T. Superior mesenteric and renal artery blood-flow-velocity measurements in neonates: technique and interobserver reliability. Pediatr Radiol 1995;25:145-8.

23 Swensson RE, Valdez-Cruz LM, Sahn DJ, et al. Real-time doppler color flow mapping for detection of patent ductus doppler color flow mapping for detection of pate

24 Macdonald PD, Paton RD, Logan RW. Neonatal endothelin-1 concentrations in term infants. Arch Dis Child 1994;70:F223-4

25 Malamitsi-Puchner A, Economou E, Efstathopoulos T, Sevastjadou S, Hadzista-matiou Z, Nicolopoulos D. Endothelin 1-21 plasma concentrations on days 1 and 4 of life in healthy and ill preterm neonates. Biol Neonate 1995;87:317-21.

26 Aranda JV, Monin P, Beharry K, Bairam A, Vert P. The effect of endothelin-1 on the cerebrovascular response to hypoxia and hypercapnia in the newborn. Semin Perinatol 1992;16:196-9.

27 Charpie JR, Schreur KD, Papadopoulos SM, Clinton Webb R. Endothelium dependency of contractile activity differs in infant and adult vertebral arteries. F Clin Invest 1994;93:1339-43.

28 Kobari M, Fukuuchi Y, Tomita M, Tanahashi N, Konno S, Takeda H. Constriction/dilatation of the cerebral microvessels by intravascular endothelin-1 in cats. 7 Cereb Blood Flow Metab 1994;14:64-9.

29 Blauw GJ, Westendorp RG, Srivastava N, et al. Hypoxiainduced arterial endothelin does not influence peripheral vascular tone. I Cardiovasc Pharmacol 1995;26:S242-3.

30 Bhat R, John E, Chari G, Shankararao R, Fornell L, Gulati A, Vidyasagar D. Renal actions of endothelin-1 in newborn piglets: dose effect relation and the effects of receptor antagonist (BQ-123) and cyclooxygenase inhibitor (indome-thacin). F Lab Clin Med 1995;126:458-69. 31 Nova A, Sibai BM, Barton JR, Mercer BM, Mitchell MD.
Maternal plasma endo-thelin is increased in preeclampsia. Am $\mathcal{F}$ Obstet Gynecol 1991;165:724-7.

32 Schiff E, Ben-Baruch G, Peleg E, et al. Immunoreactive circulating endothelin-1 in normal and hypertensive pregnan-cies. Am $\mathcal{F}$ Obstet Gynecol 1992;168:624-8.

33 Clark BA, Halvorson L, Sachs B, Epstein FH. Plasma endothelin levels in pre-eclampsia: elevation and correlation with uric acid levels and renal impairment. $A m \mathcal{F}$ Obstet Gynecol 1992;166:962-8. 
34 Kraayenbrink AA, Dekker GA, van Kamp GH, van Geijn HP. Endothelial vaso-active mediators in pre-eclampsia. Am Obstet Gymecol 1993;169:160-5.

35 Perry KG, Martin RW, Blake PG, Burnett JC, Martin JN The impact of parturition and severe pre-eclampsia on gestational endothelin concentrations. I Matern Fetal Invest 1994;4:129-32.

36 Taylor GA, Short BL, Walker LK, Trayatman RJ. Intracranial blood flow: quantification with duplex Doppler and color Doppler flow US. Radiology 1990;176:231-6.

37 Altman DI. Cerebral blood flow in premature infants: regulation, measurement and pathophysiology of intraventricu-
lar haemorrhage. In: Polin RA, Fow WF,eds. Fetal and Neonatal Physiology. Philadelphia: J B Lippincott, 1992;1587-97.

38 Coombs RC, Morgan MEI, Durbin GM, Booth IW, McNeish AS. Abnormal gut blood flow velocities in neonates at risk of necrotising enterocolitis. F Pediatr Gasneonates at risk of necrotising
troenterol Nutr 1992;15:13-19.

39 Kempley ST, Gamsu HR, Vyas S, Nicolaides K. Effects of intrauterine growth retardation on postnatal visceral and intrauterine growth retardation on postnatal visceral and 18 .

40 Wong S-N, Lo RN-S, Hui PW. Abnormal renal and splanchnic arterial Doppler pattern in premature babies with symptomatic patent ductus arteriosus. $\mathcal{F}$ Ultrasound Med 1990;9:125-30.

41 Coombs RC, Morgan MEI, Durbin GM, Booth IW, McNeish AS. Gut blood flow velocities in the newborn: effects of patent ductus arteriosus and parenteral indomethacin. Arch Dis Child 1990; 65:1067-71.

42 Leidig E. Doppler analysis of superior mesenteric artery blood flow in preterm infants. Arch Dis Child 1989:64:47680.

43 Van Bel F, van Sweiten PHT, Guit GL, Schipper J. Superior mesenteric artery blood flow velocity and estimated volume flow: duplex doppler US study of preterm and term neonates. Radiology 1990;174:165-69.

44 Gladman G, Sims DG, Chiswick ML. Gastrointestinal blood flow velocity after the first feed. Arch Dis Child 1991;66:17-20.

45 Ohlsson A, Fong K, Ryan ML, Yap L, Myhr TL. The effect of physiological variables on mean peak on mean peak cerebral blood flow velocity in preterm ventilated neonates. Pediatr Res 1994;36:33A.

46 Milner P, Bodin P, Loesch A. Rapid release of endothelin and ATP from isolated aortic endothelial cells exposed to increased flow. Biochem Biophys Res Comm 1990;170:64956.

47 Pryds O, Greisen G, Lou H. Vasoparalysis associated with brain damage in asphyxiated term infants. $f$ Pediatr 1990;117:119-25.

48 Akinbi H, Abbasi S, Hilpert PL, Bhutani VK. Gastrointestinal and renal artery blood flow velocity profile in neonates with birth asphyxia. F Pediatr 1994;125:625-27. 